\title{
Mindfulness in primary care healthcare and teaching professionals and its relationship with stress at work: a multicentric cross- sectional study
}

\author{
Rosa Magallón-Botaya ${ }^{1}$, Luis Angel Pérula-de Torres ${ }^{2,3^{*}}$, Juan Carlos Verdes-Montenegro Atalaya ${ }^{4}$, \\ Celia Pérula-Jiménez², Norberto Lietor-Villajos ${ }^{5}$, Cruz Bartolomé-Moreno ${ }^{1}$, Javier Garcia-Campayo ${ }^{6}$, \\ Herminia Moreno-Martos ${ }^{7}$ and the Minduudd Collaborative Study Group
}

\begin{abstract}
Background: Work stress is a common problem among the health personnel of the Spanish National Health System. The objective of this paper is to assess the state of mindfulness among Spanish primary care providers and to evaluate its potential relationship with work stress and basic labor and sociodemographic characteristics.

Methods: Cross-sectional, multi-centric study. Primary care nurses, teachers, teaching collaborators and residents assigned to six Spanish Family Medicine/Family and Community Care Departments were invited to participate $(n=$ 475). A template was designed in Google Forms, including sociodemographic and work-related variables. The state of mindfulness was measured with the Five Facet Mindfulness Questionnaire (FFMQ), while work-related stress was measured using an ordinal scale ranging from 0 to 10 points. Descriptive and inferential statistical analyses were carried out, as well as bivariate and multivariate statistics.
\end{abstract}

Results: The mean age of participants was 40,14 \pm 13.12 (range:23-65 years); 66.9\% were women, 42.5\% internal medicine residents, $29.3 \%$ family physicians, and $20.2 \%$ nurses. More than half (54.5\%) knew about mindfulness, with $24.0 \%$ have received training on it, and $22.5 \%$ were usual practitioners. The average level of mindfulness was $127.18 \pm 15.45$ (range: 89-177). The average score of stress at work was $6.00 \pm 2.44 ; 49.9 \%$ (range: $0-10$ ). $49.9 \%$ of participants scored 7 or more on the stress at work scale. There was an inverse correlation between the levels of mindfulness (FFMQ total score) and work-related stress (Spearman's $r=-0.155, p=0.003$ ). Significant relationships between the mindfulness practice and the level of mindfulness ( $F=29.80, p<0.001)$, as well as between the mindfulness practice and the level of work-related stress $(F=9.68, p=0.042)$, were also found.

(Continued on next page)

\footnotetext{
* Correspondence: langel.perula.sspa@juntadeandalucia.es

${ }^{2}$ Multi-professional Teaching Unit for Family and Community Care of Córdoba, Healthcare District of Córdoba and Guadalquivir, Institute

Maimónides of Research Córdoba (IMIBIC)/Hospital Reina Sofía/University of Córdoba, Isla de Lanzarote, 3, 14011 Córdoba, Spain

${ }^{3}$ Instittute of Health Carlos III (redIAPP 06/18), IIS-Aragon, Group B. University of Zaragoza, Zaragoza, Spain

Full list of author information is available at the end of the article
}

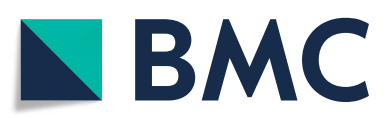

(- The Author(s). 2021 Open Access This article is licensed under a Creative Commons Attribution 4.0 International License, which permits use, sharing, adaptation, distribution and reproduction in any medium or format, as long as you give appropriate credit to the original author(s) and the source, provide a link to the Creative Commons licence, and indicate if changes were made. The images or other third party material in this article are included in the article's Creative Commons licence, unless indicated otherwise in a credit line to the material. If material is not included in the article's Creative Commons licence and your intended use is not permitted by statutory regulation or exceeds the permitted use, you will need to obtain permission directly from the copyright holder. To view a copy of this licence, visit http://creativecommons.org/licenses/by/4.0/. The Creative Commons Public Domain Dedication waiver (http://creativecommons.org/publicdomain/zero/1.0/) applies to the data made available in this article, unless otherwise stated in a credit line to the data. 
(Continued from previous page)

Conclusions: Levels of mindfulness in primary care health providers were in line with those levels observed in other groups of health professionals. Half of all of the primary care providers suffered from a high degree of stress. Although weak, inverse relationships were observed between levels of mindfulness and stress at work, with lower values of stress at work among those who practiced mindfulness.

Trial registration: NCT03629457.

Keywords: Mindfulness, Work stress, Subjective well-being, Primary health care professionals, Health services research

\section{Background}

A great number of healthcare professionals complain about their work conditions: excess of health care pressure, increasingly demanding users seeking treatment for their health problems and needs, a lack of sufficient time for training and re-training, as well as the perceived lack of support by managers and their superiors [1-3]. Professionals who also take on training tasks, suffer situations of even more overload. Many studies have suggested the need to solve this with an integral form of tackling the physical and psychological consequences of work stress in healthcare professionals. Not merely adopting measures at a work organization level and their work conditions, but also providing individual tools to handle stress, based on acceptance of reality and emotional self-regulation $[4,5]$.

In the specific area of post-graduate teaching, Spain boasts a high-quality model of specialized training [6]. The Training Program for Resident Intern Specialists (RIS) from the Family and Community Medicine specialty is 4 years long and the program for Family and Community Nursing is 2 years. Although the goal is for the young training doctor or nurse, to take on responsibilities in different areas of competence, both healthcare, teaching and research, in a progressive manner, stress is inevitable, especially in the emergency department [7]. An important figure in the training process of the RIS is the personal tutor. Carrying out this task of teaching implies a major work load in addition to the regular everyday work activity.

The term "mindfulness" originates in Buddhist teachings and implies a state, in which the individual focuses their present on the task at hand, without the mind digressing to the future or past, and without the sensation of attachment or rejection. Mindfulness is a quality that can be developed through appropriate training [8] and that generates significant benefits in the physical and mental health of those engaging in it. The level of mindfulness appears to be an influential factor in the determination of the degree of work-related stress experienced by healthcare professionals. In fact, diverse intervention studies and meta-analyses carried out on healthcare professionals, have demonstrated that meditation techniques increase the levels of mindfulness and improve coping skills for workrelated stress $[9,10]$.

We have barely found studies conducted in our field that examine the state of mindfulness in primary care healthcare professionals, on the one hand, with the potential relationship between the knowledge, training and the practice of mindfulness; and on the other, with the level of work-related stress perceived $[9,11]$. Furthermore, we are unaware of its relationship with the teaching and learning condition of the professional. Therefore, this study aims to determine the state of mindfulness between Spanish primary care professionals, as well as to assess potential associations between the levels of mindfulness, the practice of mindfulness exercises and the degree of workrelated stress. All this focused, especially, to the teaching areas, comparing the results according to the primary care professional profile.

\section{Methods}

Design

A cross-sectional study was conducted, using a selfadministered online questionnaire, by healthcare professionals in the primary care teaching and care environment.

\section{Participants and procedure}

The inclusion criteria were: 1) To be a family doctor, a family medicine resident, or a primary care nurse; and 2) To provide informed consent for participation in the study. The study population consisted of primary care professionals from six Teaching Departments of the Spanish National Health System of different dimensions, according to the population density of each territory, distributed across the Spanish geography, $(\mathrm{N}$ total $=802$; Córdoba $N=$ 256; Almería, $N=147$; Jaén, $N=185$; Burgos, $N=64$; Ponferrada, $N=63$; and Zaragoza, $N=87$ ). Of the surveyed participants professionals, 297 were teachers and 595 were Resident Intern Specialists in Family and Community Medicine/Nursing. For comparison purposes, a subsample of 267 nurses working in non-teaching care settings, in the Córdoba province, were also surveyed. The results from this sample have already been published [12]. Based on the results of previous research [12], it was necessary to recruit 
at least 433 participants in the present study. The sample size was calculated assuming a precision of $\pm 3.5 \%$, a confidence of $95 \%$, and an expected knowledge about mindfulness of $36.5 \%$. The calculations have been made with the GRANMO program (http://www.imim.cat/ofertadeserveis/ software-public/granmo/). For the recruitment of the subjects, the study was disseminated by sending an email to all those responsible for the participating centers.

\section{Measurements}

The participation procedure was carried out electronically, through an online questionnaire created by our research group in Google Forms. The questionnaire was originally tested on a subsample of four subjects, in order to check its comprehensibility. The questionnaires were anonymous and the appropriate mechanisms were established to safeguard the confidentiality of the information collected.

Mindfulness was the main variable and it was measured using the Five Facet Mindfulness Questionnaire (FFMQ), validated for the Spanish population [13]. The FFMQ consists of 39 items and five dimensions: observation, description, acting conscientiously, lack of judgment and lack of reactivity. The participants answered to each item on a Likert scale, with response items ranging from 1 (never or rarely true) to 5 (very often or almost true). The FFMQ permits the computation of a total mindfulness score, from the total of all of its dimensions, such that higher scores mean greater levels of mindfulness. The psychometric characteristics of the FFMQ in the Spanish population are appropriate, with a response range from between 89 and 177 . Computation of internal consistency for the present data showed an alpha coefficient of 0.88 for the FFMQ total score. In the correlations with other scales, the FFMQ validated for the Spanish population showed an expected and significant relationship with almost every scale, except the observation dimension [13]. In addition to the state of mindfulness, which was measured by the FFQM, other variables were also included, such as age, gender, professional profile, work site, labor seniority, degree of awareness of the mindfulness concept, prior training, level of practice and frequency. The level of work-based stress was also assessed for the prior 2 weeks, using a visual analogue ordinal scale. Participants were asked to rate their work-based stress using the following question: On a scale from 0 (none) to 10 (maximum), what degree of work stress have you had in the last 2 weeks at your usual job?. In previous studies, this type of scale has been found to be suitable for the assessment of perceived stress [14].

\section{Ethical considerations}

The study protocol was approved by the Ethics and Clinical Research Committee of Córdoba, (number 275; referencie 3845). Information on the study's objective was provided online to the professionals who agreed to participate via informed consent prior to completing the questionnaire. In accordance with personal data protection and confidentiality regulations (European Regulation on data protection and in accordance with Organic Law 3/2018 on Personal Data Protection and Digital Rights Guarantee).

\section{Statistical analysis}

Data centralization, dispersion and position variables were used, as well as absolute and relative frequencies to describe the variables that were the subject of the study, based on their distribution. Confidence intervals were calculated at $95 \%$ (95\% CI) for the main estimators. In order to examine the relationship between the sociodemographic and labor variables, and the degree of mindfulness or the level of work-related stress, bivariate analyses were conducted, applying the Spearman's correlation coefficient (r), the Student's t test and the ANOVA test (upon verifying the normality of the variables through the Kolmogorov-Smirnov test; in the contrary case, either the Spearman's correlation coefficient, Mann-Whitney U test or the Kruskal-Wallis test was used). Multivariate analyses were also applied, through application of multiple linear regression models, using the dependent variables of mindfulness and level of work-related stress and the independent variables of age, gender, profession, amount of time worked and knowledge, training and practice of mindfulness, in model 1 and of these only those whose $p$ value was less than 0.05 were considered in model 2 . The statistical significance level was established at alpha error $\leq$ 0.05. The SPSS (Statistical Package for the Social Sciences) v.22 was used for data analysis. SPSS is a statistical computer program widely used in the social and applied sciences (https://www.ibm.com/products/spss-statistics).

\section{Results}

The survey was completed by 475 primary care health workers, with an overall response rate of $44.5 \%$. The response rate varied between $47.2 \%$ of the members of the teaching units and $35.9 \%$ of the non-teaching nurses. The mean age was 40.14 $\pm 13.12-\mathrm{SD}$ - (range: 23-65 years). $66.9 \%$ of the respondents were women. $42.5 \%$ were resident intern physicians; $29.3 \%$ were family doctors and $20.2 \%$ were nurses. Of the physicians, $61.0 \%$ had worked for over 20 years, as was the case with $42.7 \%$ of the nurses, whereas $91.2 \%$ of the resident intern physicians had been working for less than 4 years.

The mean score for work-related stress was $6.00 \pm 2.44$ (range: $0-10,95 \%$ CI: $5.78-6.22$ ), with $49.9 \%$ of the 
participants scoring 7 or higher on the work-related stress scale.

Regarding mindfulness, $54.5 \%$ stated that they knew the meaning of this concept; $24.0 \%$ of them, had received prior training on its practice, while 22.5\% currently engaged in mindfulness exercises. Of this 22.5 , $4 \%$ of the surveyed participants practiced mindfulness daily, while $4.2 \%$ practiced it from two to three times a week and $14.3 \%$ did so occasionally.

The mean level of mindfulness, assessed with the FFMQ questionnaire, was $127.18 \pm 15.45$ (range: $89-177$; 95\% CI: 125.79-128.57).

As seen in Table 1, using bivariate analysis, it was possible to observe statistically significant differences between the levels of mindfulness and age $(p<0.001$; highest mean score on the FFMQ for the oldest professionals), professional category $(p<0.001$; lowest score for the resident intern physicians), amount of time worked ( $p<0.001$; higher mean score for professionals having worked for the longest amount of time), and training or prior practicing of mindfulness $(p<0.001)$. No significant differences were found based on gender ( $p=0.910)$ or prior knowledge of the concept of mindfulness $(p=0.145)$.

Table 2 shows a statistically significant association between the stress-related work situation of the professional and his/her age $(p<0.001)$, professional profile $(p<0.001)$, amount of time worked $(p<0.001)$, and the practice of mindfulness $(p<0.001)$. In the bivariate analysis shown in this table, no significant differences were found, with regards to gender $(p=0.714)$, knowledge ( $p=0.727)$ or prior training in mindfulness $(p=0.251)$.

A direct, statistically significant relationship was found between the degree of exercise practice and level of

Table 1 Relationship between the study variables and the state of mindfulness through a bivariate analysis

\begin{tabular}{|c|c|c|}
\hline Variables & Mean \pm SD $(95 \% \mathrm{Cl}$ of the mean) & $P$ value \\
\hline Age (years): & & $<0.001^{*}$ \\
\hline -Under 30 & $121.94 \pm 13.49(119.95-123.90)$ & \\
\hline -From 30 to 45 & $129.75 \pm 14.93(126.81-132.70)$ & \\
\hline-46 or over & $130.81 \pm 16.14(128.51-133.10)$ & \\
\hline Gender: & & $0.910^{* *}$ \\
\hline -Male & $127.29 \pm 14.68(124.98-129.61)$ & \\
\hline -Female & $127.12 \pm 15.84(125.37-128.87)$ & \\
\hline Professional category: & & $<0.001^{*}$ \\
\hline -Family physician & $130.62 \pm 15.29(128.31-132.92)$ & \\
\hline -Nurse & $131.19 \pm 16.39(127.88-134.49)$ & \\
\hline - Internal medicine residents & $122.42 \pm 13.83(120.52-124.32)$ & \\
\hline Amount of time worked: & & $<0.001^{*}$ \\
\hline -Less than 4 years & $122.59 \pm 13.75(120.70-124.48)$ & \\
\hline -From 5 to 10 years & $130.59 \pm 16.76(125.78-135.40)$ & \\
\hline -From 11 to 20 years & $127.35 \pm 15.83(123.63-131.07)$ & \\
\hline -Over 20 years & $132.36 \pm 15.45(129.88-134.84)$ & \\
\hline Aware of mindfulness: & & $0.145^{* *}$ \\
\hline -Yes & $128.12 \pm 15.87(126.18-130.07)$ & \\
\hline$-\mathrm{No}$ & $126.05 \pm 15.45(124.05-128.04)$ & \\
\hline Has received training on mindfulness: & & $<0.001^{* *}$ \\
\hline$-\mathrm{Si}$ & $130.73 \pm 18.01(127.39-134.07)$ & \\
\hline$-\mathrm{No}$ & $126.06 \pm 14.40(124.57-127.55)$ & \\
\hline Practices mindfulness: & & $<0.001^{*}$ \\
\hline -Every day & $145.53 \pm 17.85(136.92-154.13)$ & \\
\hline -From 2 to 3 times/week & $136.00 \pm 15.82(128.59-143.41)$ & \\
\hline -Occasionally & $129.35 \pm 15.82(123.87-126.83)$ & \\
\hline -Never & $125.35 \pm 14.43(123.87-126.83)$ & \\
\hline
\end{tabular}


Table 2 Relationship between the study variables and the level of work-related stress through a bivariate analysis

\begin{tabular}{|c|c|c|}
\hline Variables & Mean \pm SD $(95 \% \mathrm{Cl}$ of the mean) & $P$ value \\
\hline Age (years): & & $<0.001^{*}$ \\
\hline -Under 30 & $5.38 \pm 2.61(5.00-5.77)$ & \\
\hline -From 30 to 45 & $6.36 \pm 2.40(5.88-6.83)$ & \\
\hline-46 or over & $6.39 \pm 2.18(6.08-6.70)$ & \\
\hline Gender: & & $0.714^{* *}$ \\
\hline -Male & $6.10 \pm 2.31(5.76-6.46)$ & \\
\hline -Female & $5.95 \pm 2.50(5.67-6.22)$ & \\
\hline Professional category: & & $<0.001^{*}$ \\
\hline -Family physician & $6.34 \pm 2.03(6.04-6.65)$ & \\
\hline -Nurse & $6.51 \pm 2.39(6.02-6.99)$ & \\
\hline - Internal medicine residents & $5.47 \pm 2.68(5.10-5.83)$ & \\
\hline Amount of time worked: & & $<0.001^{*}$ \\
\hline -Less than 4 years & $5.40 \pm 2.66(5.03-5.76)$ & \\
\hline -From 5 to 10 years & $6.22 \pm 2.08(5.63-6.82)$ & \\
\hline -From 11 to 20 years & $6.72 \pm 2.13(6.22-7.22)$ & \\
\hline -More than 20 years & $6.40 \pm 2.20(6.04-6.76)$ & \\
\hline Aware of mindfulness: & & $0.727^{* *}$ \\
\hline -Yes & $6.02 \pm 2.67(5.75-6.30)$ & \\
\hline$-\mathrm{No}$ & $5.96 \pm 2.64(5.61-6.32)$ & \\
\hline Has received training on mindfulness: & & $0.251^{* *}$ \\
\hline -Yes & $5.85 \pm 2.37(5.41-6.29)$ & \\
\hline$-\mathrm{No}$ & $6.04 \pm 2.47(5.79-6.30)$ & \\
\hline Practices mindfulness: & & $0.040^{*}$ \\
\hline -Every day & $4.58 \pm 2.34(3.45-5.71)$ & \\
\hline -From 2 to 3 times/week & $6.70 \pm 1.84(5.84-7.56)$ & \\
\hline -Occasionally & $5.96 \pm 2.39(5.38-6.53)$ & \\
\hline -Never & $6.04 \pm 2.47(5.79-6.29)$ & \\
\hline
\end{tabular}

SD Standard deviation, 95\% Cl 95\% confidence interval

* Kruskal-Wallis Test; ** Mann-Whitney U

mindfulness, assessed in the FFMQ questionnaire $(\mathrm{F}=14.389, p<0.001)$. A slight, but significant negative correlation was also found between the level of mindfulness (FFMQ overall score) and the level of work-related stress $(r=-0.155, p=0.003)$.

In the multivariate analysis (Table 3 ), variables associated with the level of mindfulness were: age $(B=0.313$; $p<0.001)$, practice of mindfulness $(\mathrm{B}=4.614 ; p<0.001)$, and work-related stress $(\mathrm{B}=-1.044 ; p<0.001)$. On the other hand, as seen in Table 4, levels of work-related stress are associated with age $(B=0.036 ; p<0.001)$ and level of practicing of mindfulness $(\mathrm{B}=-0.334 ; p<0.001)$. In contrast with the findings from the bivariate analysis, as seen in Tables 3 and 4, the multivariate analysis did not reveal significant relationships, between professional profile and levels of mindfulness, or perceived workrelated stress.

\section{Discussion}

Half of the healthcare professionals appear to suffer from a high degree of work-related stress. There is a positive, though weak, correlation between the degree of mindfulness and work stress, with less stress among those who practice mindfulness. In this sense, the state of mindfulness in primary care healthcare providers appears to be in line with that observed in other professional healthcare groups [15], with a level of knowledge more than acceptable, although much lower in terms of practice.

This finding supports the potential protective role of mindfulness in the reduction of work-related stress. Meditative practice might be associated with greater levels of mindfulness, and this, in turn, to the reduction of perceived work -related stress. Some prior studies are in line with this explanatory model $[16,17]$. 
Table 3 Variables associated with the state of mindfulness through a multivariate analysis

\begin{tabular}{|c|c|c|c|c|c|c|c|c|}
\hline \multirow[t]{3}{*}{ Variables } & \multicolumn{4}{|l|}{ Model 1} & \multicolumn{4}{|c|}{ Model 2} \\
\hline & \multirow[t]{2}{*}{ B } & \multicolumn{2}{|l|}{$95.0 \% \mathrm{Cl}$ for $\mathrm{B}$} & \multirow[t]{2}{*}{$\mathrm{p}$} & \multirow[t]{2}{*}{ B } & \multicolumn{2}{|l|}{$95.0 \% \mathrm{Cl}$ for $\mathrm{B}$} & \multirow[b]{2}{*}{$\mathbf{p}$} \\
\hline & & Lower Bound & Upper Bound & & & Lower Bound & Upper Bound & \\
\hline Age & 0.202 & -0.015 & 0.419 & 0.068 & 0.313 & 0.211 & 0.414 & $<0.001$ \\
\hline Gender & 0.533 & -2.276 & 3.343 & 0.709 & - & - & - & - \\
\hline Profession & -1.071 & -3.626 & 1.485 & 0.411 & - & - & - & - \\
\hline Time working in current position & 0.286 & -0.681 & 1.254 & 0.561 & - & - & - & - \\
\hline Awareness of mindfulness & 1.039 & -1.970 & 4.048 & 0.498 & - & - & - & - \\
\hline Training in mindfulness & -0.463 & -4.047 & 3.122 & $0 ., 800$ & - & - & - & - \\
\hline Mindfulness practice & 4.727 & 2.720 & 6.734 & $<0.001$ & 4.614 & 2.845 & 6.383 & $<0.001$ \\
\hline Work-related stress & -1.062 & -1.603 & -0.520 & $<0.001$ & -1.044 & -1.579 & -0.508 & $<0.001$ \\
\hline Intercept & 118.461 & - & - & - & 114.675 & - & - & - \\
\hline
\end{tabular}

Maximum model (model 1). Parsimonious model (model 2). Dependent variable: mindfulness (FFMQ); Coefficient of determination of model 1: $R^{2}=0.163(F=11.35 ; p<0.001$ ); Coefficient of determination of model $2: \mathrm{R}^{2}=0.161(\mathrm{~F}=29.80 ; p<0.001) . n=474 ; 95 \% \mathrm{Cl} 95 \%$ confidence interval

The multivariate analysis demonstrates that there are no differences between the different professional profiles that were analyzed: physicians, nurses and residents in training, both with respect to the level of mindfulness as well as the level of work-related stress. These variables have been studied separately for the distinct types of professionals [18]. This study brings the novelty of comparing at the same time the level of mindfulness and stress between different professional groups. There appears to be a discrepancy in this result, since a priori it appears that stress may be more closely related to the level of professional responsibility.

It has been sufficiently accredited that emotional intelligence prevents burnout and work-related stress, not only in physicians but also in nurses $[19,20]$. And the practice of mindfulness is another strategy used for emotional reinforcement. It is a technique which, when put into practice, eliminates (in theory) the anticipatory anxiety, which is a trigger for work-related stress. Some studies carried out in primary health care professionals, show that meditation techniques serve to improve coping with stress and empathy [16]. It is likely that the effectiveness of these programs, in preventing workrelated stress is closely related to the capacity for selfcompassion [21]. An attitude of self-compassion towards oneself, is one of the key elements of mindfulness, since it permits us, to better manage difficult emotions, such as fear, anger, sadness or doubt.

Our multidisciplinary research group has also examined the specific effect of mindfulness on nursing [12] and other primary care professionals, as we have detailed previously [21].

In the study carried out among the nursing staff [12] it was found that those nurses who practiced mindfulness had lower levels of work stress than those who did not. Within the dimensions of the FFMQ, they showed a greater capacity for observation, in addition to a higher level of global mindfulness, compared to other primary

Table 4 Variables associated with the state of work-related stress through a multivariate analysis

\begin{tabular}{|c|c|c|c|c|c|c|c|c|}
\hline \multirow[t]{3}{*}{ Variables } & \multicolumn{4}{|c|}{ Model 1} & \multicolumn{4}{|c|}{ Model 2} \\
\hline & \multirow[t]{2}{*}{ B } & \multicolumn{2}{|l|}{$95.0 \% \mathrm{Cl}$ for $\mathrm{B}$} & \multirow[t]{2}{*}{$p$} & \multirow[t]{2}{*}{ B } & \multicolumn{2}{|l|}{$95.0 \% \mathrm{Cl}$ for $\mathrm{B}$} & \multirow[b]{2}{*}{$\mathrm{p}$} \\
\hline & & Lower Bound & Upper Bound & & & Lower Bound & Upper Bound & \\
\hline Age & 0.000 & -0.037 & 0.036 & 0.976 & 0.036 & 0.019 & 0.052 & $<0.001$ \\
\hline Gender & 0.036 & -0.436 & 0.507 & 0.882 & - & - & - & - \\
\hline Profession & -0.035 & -0.464 & 0.394 & 0.871 & - & - & - & - \\
\hline Time working in current position & 0.186 & 0.024 & 0.347 & 0.024 & - & - & - & - \\
\hline Awareness of mindfulness & -0.318 & -0.822 & 0.187 & 0.216 & - & - & - & - \\
\hline Training in mindfulness & 0.241 & -0.360 & 0.843 & 0.431 & - & - & - & - \\
\hline Mindfulness practice & -0.378 & -0.714 & -0.043 & 0.027 & -0.334 & -0.631 & -0.037 & $<0.001$ \\
\hline Intercept & 5.771 & - & - & - & 5.015 & - & - & - \\
\hline
\end{tabular}

Maximum model (model 1). Parsimonious model (model 2). Dependent variable: perceived work-based stress; Coefficient of determination of model 1: $R^{2}=0.054$ $(F=8.86 ; p=0.002)$; Coefficient of determination of model $2: R^{2}=0.039(F=9.68 ; p<0.001) . n=474 ; 95 \% C l 95 \%$ confidence interval 
care health professionals, even higher than in those who received a training program in mindfulness [21].

Recently, Aranda et al. [22] evaluated the effectiveness of an eight-week training program on mindfulness and self-compassion, to reduce stress levels and burnout in primary care professionals. Despite the limited response to the program, it suggests the potential benefits of promoting mindfulness and practices of self-compassion in the healthcare environment.

Other interesting experiences are available, such as the program proposed approximately one decade ago, by Krasner, Epstein et al. [23], with primary care physicians. The results were conclusive: the participation in a communication program, was associated with short and long-term improvements, in well-being and attitudes associated with patient-centered care.

Delving into the education field, it is especially interesting the fact observed by Beddoe et al. [24] that «being attentive» not only decreases personal stress in students of a training intervention, but also improved their empathetic attitude and decreased the tendency to be loaded down with negative emotions of others.

Also, in the teaching environment, certain experiences in the area of effectiveness of mindfulness in education have had positive results, not only for teachers [25].but also for students [26], with substantial improvement taking place in academic performance.

There is a peculiarity of our study that makes it different from others. We are in a special teaching and learning environment: healthcare. Teachers and residents share expectations and responsibilities of teaching and learning with the care activity and the stress that may be caused by this situation. The work of the teacher tutors of the Family Medicine Departments, does not differ substantially from that of the purely educational environment. But perhaps the complementarity of their teaching competencies, with the clinical practice, makes the latter considered a priority undermining the teaching activity.

The effectiveness of mindfulness techniques on the professionals (such as physicians and nursing residents) in the learning process, has been demonstrated in the past [27] as well as recently [28]. However, it does not appear that these evidences had been accompanied by its serious and ongoing implementation to reduce stress in the areas that have been studied.

In our study, we analyze the prior level of mindfulness and its potential relationship with some variables. We have not found differences in mindfulness nor in the level of workrelated stress, by professional groups: in nurses, physicians and residents, suggesting that intervention programs may be useful for all of the professional groups.

There are no differences detected in terms of gender, but there were, with regards to age. In this sense, one of the pending areas to be addressed, also suggested in other studies, is the lack of assessment of the long-term effectiveness of the intervention programs.

An inverse relationship was observed between the level of practicing of mindfulness exercises and the level of work-related stress, such that, with greater practice levels, there were lower work-related stress levels. This coincides with the results from past studies and supports the need for the practicing of mindfulness in the care and training environments.

Limitations include the sample composition (unless it can be demonstrated that it maintains the same percentages by occupation as the general Spanish population). It should be mentioned that at least the sample size is high, taking into account the type of statistical analysis carried out, therefore the statistical power was adequate. Another limitation is the use of a scale with only one item to assess perceived workrelated stress, since this is a complex construct. However, this work is an exploration that should be confirmed in future studies. The final limitation is the type of design used, which, being cross-sectional, does not permit us to establish causal relationships. Crosssectional data is always limited to examine a research question which entails a relationship (mindfulness reduces stress). But maybe it is the other way round and those people who have less stress, have more time to do practice mindfulness. So, in future studies, the potential causal relationships between variables derived from the observed association should be studied using appropriate designs.

\section{Conclusions}

Given the high percentage of primary care providers who experience work-related stress, and the fact that Mindfulness-Based Interventions seem to be useful to reduce this problem, health authorities and managers in charge of continuous training programs should take them into account in the primary care setting.

Mindfulness-Based Interventions are very versatile techniques, ideal for primary care contexts or similar, and that achieve their greatest degrees of effectiveness not only in patients with symptoms of stress, anxiety or depression, but also in health professionals. It is necessary to carry out intervention studies directed at these health professionals in order to verify if the standardized programs of instruction in mindfulness manage to reduce the level of stress and burnout.

\section{Supplementary Information}

The online version contains supplementary material available at https://doi. org/10.1186/s12875-021-01375-2.

Additional file 1 


\section{Abbreviations}

FFMQ: Five Facet Mindfulness Questionnaire; RIS: Resident Intern Specialists; SD: Standard deviation; 95\% Cl: 95\% confidence interval; SPSS: Statistical Package for the Social Sciences

\section{Acknowledgements}

The authors would like to express their gratitude to the members of the coordinating organism of the PAPPS and the Spanish Society of Medicine of Family and Community (semFYC) for supporting this project.

\section{Authors' contributions}

$R M, J V, L P$ and CP designed and developed the study protocol. LP, CB, HM, $J G$ and RM conducted the study and collected the data. LP and RM analyzed the data and wrote the manuscript. All authors interpreted the data, and read and approved the final manuscript. NL and JG provided critical revisions.

\section{Funding}

The project has received funding from DGA group (B17-17R) and the Network for Prevention and Health Promotion in Primary Care (REDIAPP) grant from the Instituto de Salud Carlos III (ISCIII) of the Spanish Ministry of Economy and Competitiveness, co-financed with European Union ERDF funds (RD16/0007/0005). The role of the funding body has consisted in paying the costs of translation and publication of the article.

\section{Availability of data and materials}

The raw data supporting our findings is in the companion file (Supplementary Material).

\section{Ethics approval and consent to participate}

The project has been approved by the Ethics and Clinical Research Committee of the Reina Sofía Hospital in Córdoba (ref. 3845). The informed consent of the participants was requested. The written informed consent of the participants was obtained by indicating it in the data collection form used.

\section{Consent for publication}

\section{Not applicable.}

\section{Competing interests}

The authors declare that they have no competing interests.

\section{Author details}

${ }^{1}$ Family and Community Medicine Teaching Department of Zaragoza Sector 1, Institute of Health Carlos III (redIAPP 06/18), IIS-Aragon, Group B21-R17, University of Zaragoza, Zaragoza, Spain. ${ }^{2}$ Multi-professional Teaching Unit for Family and Community Care of Córdoba, Healthcare District of Córdoba and Guadalquivir, Institute Maimónides of Research Córdoba (IMIBIC)/Hospital Reina Sofía/University of Córdoba, Isla de Lanzarote, 3, 14011 Córdoba, Spain. ${ }^{3}$ Instittute of Health Carlos III (redIAPP 06/18), IIS-Aragon, Group B. University of Zaragoza, Zaragoza, Spain. ${ }^{4}$ Family and Community Medicine Teaching Department of Burgos, Burgos, Spain. ${ }^{5}$ Family and Community Medicine Teaching Department of Jaen, Jaen, Spain. ${ }^{6}$ Hospital Universitario Miguel Servet, Zaragoza, Spain. ${ }^{7}$ Multi-professional Teaching Unit for Family and Community Care of Almeria, Almeria, Spain.

\section{Received: 19 March 2020 Accepted: 17 January 2021}

\section{Published online: 02 February 2021}

\section{References}

1. Vilà M, Cruzate C, Orfila F, Creixell J, González MP, Davins J. Burnout y trabajo en equipo en los profesionales sanitarios de Atención Primaria. Aten Primaria. 2015;47(1):25-31.

2. Prieto Albino L, Robles Agüero E, Salazar Martínez LM, Daniel VE. Burnout en médicos de Atención Primaria de la provincia de Cáceres. Aten Primaria. 2002;29(5):294-302.

3. Matía Cubillo AC, Cordero Guevara J, Mediavilla Bravo J, Pereda Riguera MJ, González Castro ML, González SA. Evolución del burnout y variables asociadas en los médicos de Atención Primaria. Aten Primaria. 2012;44(9): 532-9.
4. Benito E, Arranz P, Cancio H. Herramientas para el autocuidado del profesional que atiende a personas que sufren. FMC. 2011;18(2):59-65.

5. Grossman P, Niemann L, Schmidt S, et al. Mindfulness-based stress reduction and health benefits. A metaanalysis. J Psychosom Res. 2004;57(1):35-43.

6. Fajardo A. El proceso de especialización en medicina familiar y comunitaria en España. Cambios profesionales en atención primaria en la década de 1980 Tesis Doctoral Universidad de Granada Autor: Angélica Fajardo Alcántara D.L:: Gr. 2354 - 2007 ISBN: 978-84-338-4506-1.

7. Mascarúa-Lara E, Vázquez-Cruz E, Córdova-Soriano JA. Ansiedad y depresión en médicos residentes de la especialidad en Medicina Familiar. Aten Fam. 2014;21(2):55-7.

8. García Campayo J. La práctica del «estar atento» (mindfulness) en medicina. Impacto en pacientes y profesionales. Aten Primaria. 2008:40(7):363-6.

9. Atanes ACM, Andreoni S, Hirayama MS, et al. Mindfulness, perceived stress, and subjective well-being: a correlational study in primary care health professionals. BMC Complement Altern Med. 2015;15:303 Available on: https://doi.org/10.1186/s12906-015-0823-0.

10. Derksen F, Bensing J, Lagro-Janssen A. Effectiveness of empathy in general practice: a systematic review. Br J Gen Pract. 2013;63(606):76-84.

11. Fuertes MC, Aranda G, Rezola N, Erramuzpe A, Palacios C, Ibañez B. Longterm effects of a mindfulness and self-compassion program with Primary Healthcare professionals. An Sist Sanit Navar. 2019;42(3):269-80. https://doi. org/10.23938/ASSN.0718

12. Pérula Jiménez $C$, Pérula de Torres $C$, Pérula de Torres LA, Jiménez García $C$, Vaquero Abellán M. Mindfulness en enfermería de atención primaria y su relación con el estrés laboral. Nure Inv. 2017;14:86 Available on: http://www. nureinvestigacion.es/OJS/index.php/nure/article/view/1014.

13. Cebolla A, García-Palacios A, Soler J, Guillen V, Baños R, Botella C. Psychometric properties of the Spanish validation of the Five Facets of Mindfulness Questionnaire (FFMQ). Eur J Psychiat. 2012;26(2):118-26 [cited on 2 June, 2016]. Available on: http://scielo.isciii.es/scielo.php?script=sci arttext\&pid=S0213-61632012000200005

14. Martín Asuero A, Rodríguez Blanco T, Pujol-Ribera E, Berenguera A, Moix QJ. Evaluación de la efectividad de un programa de mindfulness en profesionales de atención primaria. Gac Sanit. 2013;27:521-8.

15. Boellinghaus I, Jones FW, Hutton J. The role of mindfulness and lovingkindness meditation in cultivating self-compassion and other focused concern in health care professionals. Mindfulness. 2014:5:129-38.

16. Franco JC. Reducción de los niveles de estrés y ansiedad en médicos de atención primaria mediante la aplicación de un programa de entrenamiento en conciencia plena (mindfulness). Aten Primaria. 2010; 42(11):564-70.

17. Tirch DD. Mindfulness as a context for the cultivation of compassion. Int J Cogn Ther. 2010;3(2):113-23.

18. Demarzo MM, Montero-Marin J, Cuijpers P, Zabaleta-del-Olmo E, Mahtani KR, Vellinga A, Vicens C, López-delHoyo Y, García-Campayo J. The efficacy of mindfulness-based interventions in primary care: a meta-analytic review. Ann Fam Med. 2015;13(6):573-82

19. Peláez-Fernández MA. Burnout y variables asociadas en médicos de atención primaria. Aten Primaria. 2013;45(2):123-4.

20. Görgens-Ekermans G, Brand T. Emotional intelligence as a moderator in the stress-burnout relationship: a questionnaire study on nurses. J Clin Nurs. 2012:21:2275-85.

21. Montero-Marín J, Zubiaga F, Cereceda M, Piva Demarzo MM, Trenc P, García-Campayo J. Burnout subtypes and absence of self-compassion in primary healthcare professionals: A cross-sectional study. PLoS One. 2016; 11(6):e0157499 [cited on 2 September, 2019]. https://journals.plos.org/ plosone/article?id=10.1371/journal.pone.0157499.

22. Aranda G, Elcuaz MR, Fuertes C, Güeto V, Pascual P, Sainz de Murieta E. Evaluación de la efectividad de un programa de mindfulness y autocompasión para reducir el estrés y prevenir el burnout en profesionales sanitarios de atención primaria. Aten Primaria. 2018;50(3):141-50.

23. Krasner MS, Epstein RM, Beckman H, Schuman AL, Chapman B, Mooney CJ, et al. Association of an educational program in mindful communication with burnout, empathy and attitudes among primary care physicians. JAMA 2009:302:1284-93.

24. Beddoe AE, Murphy SO. Does mindfulness decrease stress and foster empathy among nursing students? J Nurs Educ. 2004:43:305-12.

25. Franco C, Mañas I, Justo E. Reducción de los niveles de estrés, ansiedad y depresión en docentes de educación especial a través de un programa de mindfulness. Inclusive Educ J. 2009;2:11-22. 
26. León B. Atención Plena y rendimiento académico en estudiantes de enseñanza secundaria. Eur J Educ Psychol. 2008;1(3):17-26.

27. Shapiro SL, Schwartz GE, Bonner G. The effects of mindfulness - based stress reduction on medical and pre-medical students. J Behav Med. 1998;21: 581-99.

28. Weng H, Hung C, Liu Y, Cheng Y, Yen C, Chang C, et al. Associations between emotional intelligence and doctor burnout, job satisfaction and patient satisfaction. Med Educ. 2011;45:835-42.

\section{Publisher's Note}

Springer Nature remains neutral with regard to jurisdictional claims in published maps and institutional affiliations.

Ready to submit your research? Choose BMC and benefit from:

- fast, convenient online submission

- thorough peer review by experienced researchers in your field

- rapid publication on acceptance

- support for research data, including large and complex data types

- gold Open Access which fosters wider collaboration and increased citations

- maximum visibility for your research: over $100 \mathrm{M}$ website views per year

At $B M C$, research is always in progress. 